\title{
ANALISA PENYEBAB KEPUASAN KERJA YANG DIAKIBATKAN OLEH ETIKA KEPEMIMPINAN DAN KOMITMEN ORGANISASI KARYAWAN PT ECOSIF MULTI KREASI
}

\author{
Tekni Megaster, Ria Puspitasari \\ megastertekni@gmail.com, ria.puspita90@gmail.com \\ Dosen Fakultas Ekonomi dan Bisnis Program Studi Manajemen \\ Universitas Muhammadiyah Tangerang
}

\begin{abstract}
The purpose of this study was to analyze the Causes of Job Satisfaction Involved by Leadership Ethics and Organizational Commitment of Employees. The design of this study is a descriptive study that describes the information and characteristics of the population or phenomenon being studied. The description used is for statistical calculation, whereas survey investigation is conducted to measure the variables with questionnaires spread by 18 questions using five points LIKERT SCALE. The method used to evaluate the survey results of several studies with regression, primary data collected from the respondents and also secondary data to support information. From the results of this study indicate that there is a positive and significant relationship between leadership ethics, organizational commitment and employee job satisfaction. Data analysis used in this study is SPSS. The results of this study conclude that leadership ethics has a certain influence on organizational commitment and employee job satisfaction.
\end{abstract}

Keywords: Leadership Ethics, Organizational Commitment, Employee Job Satisfaction.

\section{PENDAHULUAN}

Seiring dengan pertumbuhan ekonomi suatu negara membawa implikasi terhadap meningkatnya kebutuhan akan bangunan , baik bangunan perkantoran, pabrik maupun bangunan pendidikan. Dengan keterbatasan pangsa pasar yang ada menyebabkan semakin ketatnya persaingan diantara perusahaanperusahaan konstruksi. Persaingan yang terjadi antara lain menyangkut kualitas pelayanan, kualitas produk ,hargakeinginan pelanggan cenderung menginginkanpelayanan yang baik, harga yang kompetitif serta produk yang benar-benar berkualitas. Untuk mencapai tujuan yang telah ditetapkan oleh perusahaan, karyawan dituntut untuk memiliki komitmen organisasi dan kepuasan kerja. Kepuasan kerja merupakan salah satu aspek psikologis yang mencerminkan perasaan seseorang terhadap pekerjaannya, seorang karyawan akan merasa puas dengan adanya kesesuaian antara kemampuan, keterampilan dan harapannya dengan pekerjaan yang 
dihadapi . Kepuasan sebenarnya merupakan keadaan yang sifatnya subyektif yang merupakan hasil kesimpulan yang didasarkan pada suatu perbandingan mengenai apa yangditerima karyawan dari pekerjaannya dibandingkan dengan yang diharapkan ,diinginkan, dan dipikirkannya sebagai hal yang pantas. Karyawan yang memiliki kepuasan kerja membuat karyawan tersebut memiliki sikap emosional yang menyenangkan dan mencintai pekerjaannya. Karyawan yang merasa senang ketika bekerja di dalam perusahaan disebabkan oleh karyawan selalu bekerja sesuai dengan etika dan prosedur yang berlaku di dalam perusahaan (Celik, Dedeoglu, dan Inanir, 2015). Pedoman Etika merupakan serangkaian etika atau perilaku yang menyangkut masalah apakah sebuah perbuatan boleh dilakukan atau tidak boleh dilakukan dalam menjalankan tugas-tugas pemsahaan. Sikap disiplin yang dimiliki oleh karyawan sangat penting untuk pertumbuhan organisasi, digunakan terutama untuk memotivasi karyawan agar dapat mendisiplinkan diri dalam melaksanakan pekerjaan baik secara perorangan maupun kelompok. Disamping itu disiplin bermanfaat mendidik karyawan untuk mematuhi dan menyenangi peraturan, prosedur, maupun kebijakan yang ada, sehingga dapat menghasilkan kinerja yang baik.

\section{TINJAUAN PUSTAKA}

Tinjauan Teori dan Telaah Hasil

Penelitian

\section{Etika Kepemimpinan}

Menumt Celik, Dedeoglu, dan Inanir (2015), etika kepemimpinan adalah sistem yang bersifat tertulis dan tidak tertulis untuk mengatur apa yang salah dan apa yang benar harus dilakukan oleh karyawan. Frisch dan Huppenbauer (2014) mendefinisikan etika kepemimpinan adalah petunjuk atau kaidah yang mengatur sikap dan perilaku karyawan ketika bekerja didalam perusahaan. Selanjutnya menurut Tumasjan, Strobel, dan Welpe (2010) memberikan pengertian etika kepemimpinan adalah aturan yang mengatur tindakan yang dilakukan oleh karyawan ketika berhubungan dan berinteraksi dengan pimpinan penlsahaan. Shin (2012) mendefinisikan etika kepemimpinan adalah suatu aturan dan norma yang mengatur komunikasi antara pimpinan dengan bawahan. Dari beberapa definisi di atas dinyatakan bahwa etika kepemimpinan adalah seperangkat aturan dan norma-norma yang berlaku didalam perusahaan yang menjadi pedoman dan aturan yang berlaku di dalam perusahaan.

\section{Tujuan Meneliti Etika Kepemimpinan}

Frisch dan Huppenbauer (2014) menemukan tujuan pembentukan etika kepemimpinan adalah untuk menciptakan komunikasi dua arah antara karyawan 
dengan pimpinan perusahaan dan menciptakan pengambilan keputusan dari dalam diri karyawan ketika menghadapi masalah di dalam perusahaan.

\section{Kepuasan Kerja}

Robbin dan Judge (2012) menyatakan pengertian kepuasan kerja adalah perasaan positif tentang pekerjaan seseorang yang rnerupakan hasildari evaluasi karakteristikkarakteristiknya Abdulla, Djebarni, dan Mellah (2011) menyebutkan definisi kepuasan kerja adalah suatu perasaan karyawan menyukai pekerjaan yang dimilikinya. Dari beberapa definisi di atas dinyatakan bahwa kepuasan kerjaadalah suatu penilaian perasaan positif terhadap pekerjaan sehingga karyawan dapatbekerja sama, membantu, dan saling menghargai, dan melakukan pekerjaan dengan baik dan maksimal yang dipengaruhi oleh gaji, pekerjaan dalam suatu organisasi, keterlibatan karyawan, rekruitmen dan seleksi, pelatihan dan pembelajaran.

\section{Tujuan Meneliti Kepuasan Kerja}

Ghazzawi (2008) membuktikan bahwa karyawan yang puas terhadap pekerjaan yang dimilikinya dapat meningkatkan prestasi kerja karyawan.

\section{Komitmen Organisasi}

Robbins dan Judge (2012) mendefinisikan komitmen organisasi adalah tingkat sampai mana seorang karyawan memihak sebuah organisasi serta tujuan-tujuan dan keinginannya untuk mempertahankan keanggotaan dalam organisas tersebut. Menurut Filstad (2011) mendefinisikan komitmen organisasi adalah suatu kedekatan emosional yang dimiliki oleh para karyawan terhadap perusahaan dan adanya keinginan dari para karyawan untuk menjadi bagian dari anggota perusahaan.

Dari beberapa peneliti yang menjelaskan mengenai pengertian komitmen organisasi makadisimpulkan bahwa komitmen organisasi adalah keinginan karyawan untuk tetap bekerja di dalam perusahaan ditandai dengan karyawan memihak organisasi serta tujuan tujuan dan keinginannya untuk mempertahankan kcanggotaan dalam organisasi tersebut.

\section{Tujuan Pembentukan Komitmen Organisasi}

Lee, Tan, dan J avalgi (2010) meneliti tujuan pembentukan komitmen organisasi adalah meningkatkan keinginan karyawan di dalam mencapai visi, misi, tujuan, dan sasaran yang telah ditetapkan oleh perusahaan.

Berdasarkan paparan diatas maka dalam penelitian ini digambarkan kerangka pemikiran sebagai berikut:

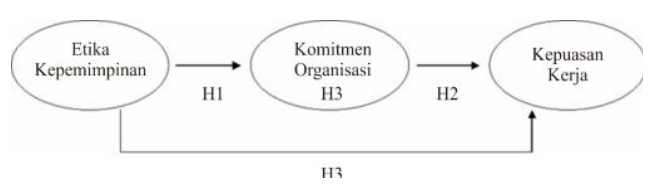

Gambar 2.1

Kerangka Konseptual 
Keterangan :

1. Pengaruh Etika Kepemimpinan Terhadap Komitmen Organisasi yang ditunjukkan padakerangka konseptual diatas adalah $\mathrm{H} 1$

2. Pengaruh Komitmen Organisasi terhadap Kepuasan kerja yangditunjukkan padakerangka konseptual diatas adalah $\mathrm{H} 2$

3. Pengaruh Etika Kepemimpinan terhadap Kcpuasan kerja yang ditunjukkan padakerangka konseptual diatas adalah H3.

\section{METODOLOGI PENELITIAN}

\section{Populasi dan Sampel}

Jumlah sampel dalam penelitian ini dilakukan dengan cara menyebarkan kuesioner kcpada 60 karyawan divisi engineering PT. Ecosif Multi Kreasi yang beralamat di Bojong Nangka, Tangerang sebagai responden dari total keseluruhan sebanyak 80 karyawan divisi engineering PT. Ecosif Multi Kreasi yang beralamat di Bojong Nangka, Tangerang. Divisi engineering dipilih untuk penelitian karena fungsi engineering merencanakan tugas tugas konstmksi pada tiga aspek, yaitu stuktur, arsitektur dan mekanikal elektrikal. Dalam penelitian ini cara penentuan jumlah sampelnya adalah menggunakan rumus Slovin dengan perhitungannya sebagai berikut .

\section{Instrumentasi dan Pengumpulan Data}

Dalam penelitian ini menggunakan kuesioner sebagai instrument pengumpulan data, yaitu dengan menyebarkan kuesioner kepada 60 karyawan divisi engineering PT. Ecosif Multi Kreasi yang beralamat di Bojong Nangka, Tangerang, yang digunakan untuk mengukur fenomena sosial yang diamati pada masing-masing variable. Untuk mendapatkan instrument penelitian yang tepat dan terukur maka sebelumnya dilakukan uji validitas dan reabilitas terhadap setiap item pernyataan yang ada pada setiap kuesioner. Dalam melakukan penelitian ini diperlukan data yang berhubungan dengan masalah yang akan diteliti untuk selanjutnya data tersebut dapat diolah dan kemudian dapat diambil kesimpulan. Adapun sumber data diperoleh dari:

\section{Kuesioner}

Penyebaran kuesioner dilakukan untuk memperoleh data primer dalam penelitian ini. Kuesioner merupakan teknik pengumpulan data yang dilakukan dengan cara membelikan serangkaian peltanyaan atau pernyataan tertuliskepada responden. Daftar pertanyaan berisi tentangdeskripsi data responden dan pertanyaan-pertanyaan mengenai pengaruh etika kepemimpinan terhadap kepuasan kerja melalui komitmen organisasi dengan tujuan mendapatkan data yang relevan dengan tujuan penelitian. Kuesioner yang digunakan dalam penelitian ini dibagi menjadi 3 bagian, 
yaitu: Bagian I adalah Profil Responden, Bagian II adalah Petunjuk Pengisian, dan Bagian III adalah Pertanyaan untuk Responden.

\section{Studi Pustaka}

Dalam studi pustaka, peneliti mengambil data dari buku-buku literatur, artikel, intemet, maupun data-data yang diperoleh dari penelitian terdahulu yaitu mengenai etika kepemimpinan, komitmen organisasi, dan kcpuasan kerja. Teknik pengumpulan sampel yang digunakan adalah teknik non probability sampling yaitu purposive sampling. Teknik purposive sampling adalah tcknik penentuan sampelbcrdasarkan kriteria-kriteria atau pertimbangan tertentu. Kriteria-kriteria yang digunakan dalam penelitian adalah jenis kelamin, usia, pendidikan terakhir, lama menjadi karyawan PT. Ecosif MultiKreasi. Keabsahan suatu hasil penelitian sangat ditentukan oleh alat ukur yang digunakan. Untuk mengatasi hal tersebut diperlukan dua macam pengujian yaitu pengujian validitas atau kcsahihan (test of validity) dan pengujian reliabilitas (test of reliability).

\section{Uji Validasi dan Reabilitas}

Uji validitas merupakan suatu pengujian yang diperlukan untuk melihat apakahalat ukur yang dibuat untuk penelitian menggunakan alat ukur yangtepat. Pendekatan yang dilakukan untuk mengujikan validitas alat ukur adalahdengan cara menghubungkan suatu konstruk yang diteliti dengan konstruklainnya (Hermawan, 2006). Uji validitas digunakan untuk mengukur sah atauvalid tidaknya suatu kuesioner. Suatu kuesioner dikatakan valid jikapertanyaan pada kuesioner mampu untuk mengungkapkan sesuatu yang akandiukur oleh kuesioner tersebut. Indikator Uji Validitas adalah: p-value 5 0,05(item pemyataan menunjukkan valid) dan $\mathrm{p}$ value > 0,5 (item pernyataanmenunjukkan tidak valid).

Berdasarkan hasil uji validitas diatas, dapat diketahui masing-masing item pernyataan yang digunakan dalam mengukur etika kepemimpinan memiliki nilai koefisian korelasi > 0,05, artinya masing-masing pernyataan yang digunakan untuk mengukur etika kepemimpinan dinyatakan valid.

Berdasarkan hasil uji validitas diatas, dapat diketahui masing-masing item pernyataan yang digunakan dalam mongukur komitmen organisasi memiliki nilai koefisian korelasi $>0,05$, artinya masingmasing pernyataan yang digunakan untuk mengukur etika kepemimpinan dinyatakan valid.

Berdasarkan hasil uji validitas diatas, dapat diketahui masing-masing item pernyataan yang digunakan dalam mengukur etika kepemimpinan memiliki nilai signifikan kurang dari 0,05 (p-value $<0,05$ ), afiinya masing-masing pemyataan yang digunakan 
untuk mengukur kepuasan kerja dinyatakan valid.

Berdasarkan hasil uji validitas diatas maka disimpulkan bahwa semua item kuesioner yang dijadikan alat ukur untuk variable etika kepemimpinan, komitmen organisasi, kepuasan kerja dinyatakan valid dan layak digunakan sebagai alat ukur dalam penelitian. Pengujian reliabilitas pada alat ukur perlu dilakukan untuk memastikan instrumen dari alat ukur yang digunakan untuk penelitian ini adalah konsisten dan akurat. Reliabilitas berkaitan dengan konsistensi, akurasi, dan prediktabilitas suatu alat ukur (Henawan, 2006). Dasar pengambilan keputusan uji reliabilitas ini adalah sebagai berikut:

(a) Jika koefisien Cronbach's Alpha $\geq 0,6$ $\rightarrow$ maka Cronbach's Alpha acceptable (construct reliable).

(b) Jika Cronbach's Alpha< 0,6 $\rightarrow$ maka Cronbach's Alpha poor acceptable

(construct unreliable).

Pada Tabel terlihat hasil uji validitas dari variabel diteliti yaitu etika kepemimpinan, komitmen organisasi, dan kepuasan kerja diperoleh nilai Cronbach Alpha lebih dari 0,6 (Cronbach Alpha>0,6) maka terlihat variabel yang diteliti konsisten (Reliable).

\section{IV.PEMBAHASAN HASIL \\ PENELITIAN}

\section{Deskriptif Data}

Statistik deskriptif merupakan ringkasan jawaban yang diberikan responden terhadap pernyataan-pemyataan di dalam kuesioner. Statistik deskriptif bertujuan untuk rnemberikangambaran atau deskripsi suatu data yang ditinjau dari nilai mean. Dalam analisis statistik deskriptif yang diuraikan berikut ini, nilai mean adalah nilai rata-rata dari keseluruhan responden terhadap variabel yang diteliti. Statistik deskriptif dari masing-masing variabel yaitu etika kepemimpinan, komitmen organisasi, dan kepuasan kerja

Adapun hasil statistik deskriptif untuk pernyataan etika kepemimpinan sebagai berikut:

\section{Tabel 4.4}

Statistik Deskriptif Variabel Etika Kepemimpinan

\begin{tabular}{lllc}
\hline No & Etika Kepemimpinan & $\begin{array}{l}\text { Nilai } \\
\text { Rata- } \\
\text { rata }\end{array}$ \\
\hline 1 & $\begin{array}{l}\text { Pimpinan di dalam } \\
\text { perusahaan bertingkah }\end{array}$ & \\
& & \\
& laku sesuai etika yang \\
berlaku di dalam & \\
perusahaan. & & \\
2 & $\begin{array}{l}\text { Pimpinan di dalam } \\
\text { perusahaan mengartikan }\end{array}$ & \\
& keberhasilan bukan dari \\
& hasil yang dicapai oleh \\
& karyawan tetapi cara \\
& yang dilakukan ketika \\
& bekerja di dalam \\
perusahaan. & \\
Pimpinan mendengarkan & 4,50
\end{tabular}




\section{apa yang karyawan \\ katakan. Didalam perusahaan \\ 4 Pimpinan di dalam perusahaan mengajarkan Sikap disiplin kepada karyawan agar mengikuti standar etika yang ada di dalam perusahaan \\ 5 Pimpinan di dalam perusahaan mengambil keputusan secara adil. \\ 6 Ketika karyawan mengambil keputusan, pimpinan perusahaan selalu bertanya apakah tepat untuk dilakukan. \\ 7 Pimpinan perusahaan dapat dipercaya \\ 8 Perusahaan menjalankan bisnis sesuai dengan etika dan nilai yang berlaku di dalam perusahaan. \\ 9 Pimpinan perusahaan mengetahui cara yangtepat untuk mematuhi etika yang berlaku didalam perusahaan. \\ 10 Pimpinan terhadap pemikiran karyawan. Perusahaan merasa tertarik}

Total Nilai Rata-rata :

4,42

\section{Sumber : Hasil Pengolahan dan} Penelitian menggunakan SPSS versi 21

Pada pernyataan 4.4 terlihat nilai rata-rata (Mean) responden karyawan engineering di PT Ecosif Multi Kreasi adalah 4,42 yang berarti mereka setuju, namun demikian banyak karyawan yanghampir sangat setuju tentang ditunjukkan etika kepemimpinan diperusahaan tersebut palingmayoritas adalah sebesar 4,63 maka responden terlihat setuju terhadap pernyataan bahwa pimpinan di dalam perusahaan mengajarkan sikap disiplin kepada karyawan agar mengikuti perusahaan. Hal ini sesuai dengan teori Frisch dan Huppenbauer (2014) mendefinisikan etika kepemimpinan adalah petunjuk atau kaidah yang mengatur sikap dan perilaku karyawan ketika bekerja di dalam perusahaan.

Adapun hasil statistik deskriptif untuk pernyataan komitmen organisasi sebagai berikut:

\section{Tabel 4.5}

\section{Statistik Deskriptif Komitmen Organisasi}

\begin{tabular}{|c|c|c|}
\hline No & Komitmen Organisasi & $\begin{array}{l}\text { Nilai } \\
\text { Rata- } \\
\text { rata }\end{array}$ \\
\hline 1 & $\begin{array}{l}\text { Seringkali } r \\
\text { mengatakan } \\
\text { teman bahwa perusahaan } \\
\text { merupakan tempat yang } \\
\text { sangat } \quad \text { baik untuk } \\
\text { bekerja. }\end{array}$ & 4,40 \\
\hline 2 & $\begin{array}{l}\text { Saya selalu menerima } \\
\text { pekerjaan apa pun yang } \\
\text { harus dikerjakan dari } \\
\text { perusahaan. }\end{array}$ & 4,22 \\
\hline 3 & $\begin{array}{l}\text { Saya menemukan } \\
\text { kesamaan antara nilai } \\
\text { yang dimiliki oleh saya }\end{array}$ & 4,37 \\
\hline
\end{tabular}


nilai perusahaan.

4 Saya merasa

bangga

mengatakan

kepada

orang lain yang menjadi

bagian dari perusahaan.

5 Perusahaan menjadi

inspirasi untuk saya

sehingga membuat saya

ingin meningkatkan

prestasi kerja.

6 Perusahaan merupakan

tempat yang sangat

baikuntuk bekerja.

Total Nilai Rata-rata :

\section{Sumber : Hasil Pengolahan dan}

\section{Penelitian menggunakan SPSS versi 21}

Pada pernyataan 4.5 terlihat nilai rata-rata (Mean) responden karyawan engineering di PT Ecosif Multi Kreasi adalah 4,35 yang berarti mereka setuju, namun demikian banyak karyawan yang paling mayoritas ditunjukkan sebesar 4,40 maka responden terlihat setuju terhadap pernyataan 1 dan 5 bahwa seringkali saya mengatakan kepada teman bahwa perusahaan merupakan tempat yang sangat baik untuk bekerja (item pernyataan 1) dan perusahaan menjadi inspirasi untuk saya sehingga membuat saya ingin meningkatkan prestasi kerja (item pernyataan 5). Robbins dan Judge (2012) mendefinisikan komitmen organisasi adalah tingkat sampai mana seorang karyawan memihak sebuah organisasi serta tujuan-tujuan dan keinginannya untuk mempertahankan keanggotaan dalam organisasi tersebut. Adapun hasil statistik deskriptif untuk pernyataan kepuasan kerja sebagai berikut:

Tabel 4.6

Statistik Deskriptif Kepuasan Kerja Kepuasan Kerja Nilai Rata-

rata

1 Saya merasa sangat $\quad 4,57$

puas dengan pekerjaan

yang saya miliki.

2 Saya menyukai bekerja $\quad 4,72$ didalam perusahaan.

Total Nilai Rata-rata :

4,75

\section{Sumber : Hasil Pengolahan dan} Penelitian menggunakan SPSS versi 21

Pada pernyataan 4.6 terlihat nilai rata-rata (Mean) responden karyawan engineering di PT Ecosif Multi Kreasi adalah 4,75 yang berarti mereka setuju, hal ini ditunjukkan pada karyawan yang paling mayoritas sebesar 4,72 maka responden terlihat setuju terhadap pernyataan bahwa saya menyukai bekerja di dalam perusahaan. Hal ini sesuai dengan teori Abdulla, Djebarni, dan Mellahi (2011) menyebutkan definisi kepuasan kerja adalah suatu perasaan karyawan menyukai pekerjaan yang dimilikinya 


\section{Hasil Uji Hipotesis}

Tabel 4.7

\begin{tabular}{lccc}
\hline \multicolumn{1}{c}{ Hipotesis } & $\begin{array}{c}\text { Estimate } \\
(\boldsymbol{\beta})\end{array}$ & $\begin{array}{c}\boldsymbol{p} \text { - } \\
\text { value }\end{array}$ & Keputusan \\
\hline & & & \\
\hline $\mathrm{H}_{1}:$ & 0,701 & 0,000 & $\mathrm{Ho}$ ditolak, \\
Etika & & & $\mathrm{Ha}$ diterima \\
Kepemimpinan & & & 1 \\
Komitmen & & & \\
Organisasi & & & $\mathrm{Ho}_{2}$ ditolak, \\
\hline $\mathrm{H}_{2}:$ & 0,373 & 0,000 & $\mathrm{Ha}$ diterima $^{-}$ \\
Komitmen & & & 2 \\
Organisasi & & & \\
Kepuasan Kerja & & 0,001 & $\mathrm{Ho}_{3}$ ditolak, \\
\hline $\mathrm{H}_{3}:$ & 0,410 & & $\mathrm{Ha}^{\text {diterima }}$ \\
Etika & & & 3 \\
Kepemimpinan & & & \\
Kepuasan Kerja & & & \\
\hline
\end{tabular}

Sumber : data kuesioner diolah

\section{Pengujian Hipotesis 1:}

Bunyi hipotesis null $(\mathrm{H})$ danhipotesis alternatif $(\mathrm{H})$ adalahsebagai berikut:

$\mathrm{H}_{01} \quad$ : Etika Kepemimpinan tidak berpengaruh terhadap Komitmen Organisasi.

$\mathrm{H}_{\mathrm{a} 1}$ : Etika Kepemimpinan berpengaruh terhadap Komitmen Organisasi.

Pada pengujian hipotesis 2 diketahui $p$ value $0,000<$ alpha 0,05 dengan nilai beta sebesar 0,373 maka $\mathrm{H}_{02}$ ditolak yang artinya Komitmen Organisasi berpengaruh terhadap Kepuasan Kerja. Karyawan yang memiliki keinginan untuk tetap bekerja di dalam perusahaan menimbulkanperasaan senang dari dalam diri karyawan terhadap pekerjaan yang dimilikinnya. Hal ini ditunjukan dengan perusahaan merupakan tempat yang sangat baik untuk bekerja sehingga sayamerasa sangat puas dengan pekerjaan yang saya miliki.

\section{Pengujian Hipotesis 3:}

Bunyi hipotesis null $(\mathrm{H})$ dan hipotesis alternatif $(\mathrm{H})$ adalah sebagai berikut:

$\mathrm{H}_{03} \quad$ : Etika Kepemimpinan tidak berpengaruh terhadap Kepuasan Kerja.

$\mathrm{H}_{\mathrm{a} 3}$ :Etika Kepemimpinan berpengaruh terhadap Kepuasan Kerja.

Pada pengujian hipotesis 3 diketahui $p$ value 0,001 <alpha 0,05 dengan nilai beta sebesar 0,410 maka H03 ditolak yang artinya Etika Kepemimpinan berpengaruh terhadap Kepuasan Kerja. Semakin karyawan ingin bekerja sesuai dengan etika yang berlaku di dalam perusahaan membuat karyawan ingin lebih memiliki penilaian positif terhadap pekerjaan yang dimilikinya. Hal ini ditunjukkan dengan pimpinan didalam perusahaan bertingkah laku sesuai etika yangberlaku didalam perusahaan sehingga karyawan merasa sangat puas dengan pekerjaan yangdimiliki.

\section{Pembahasan Hasil Penelitian}

\section{Hipotesis Satu}

Berdasarkan hasil uji hipotesis satu menunjukan bahwa Etika Kepemimpinan berpengaruhpositif terhadap Komitmen Organisasi. Hal tersebut menunjukkan Etika kepemimpinan diperlukan aturan-aturan yang meminimalisir gesekan antara 
kepentingan. Begitu juga dalamsebuah organisasi, selain aturan tertulis, diperlukan juga aturan tidak tertulis yang mengaturhubungan antarrekankerja untuk memastikan tercapainya tujuan organisasi tersebut.Semakin baik etika yang berlaku di dalam perusahaan membuat karyawan semakin ingin tetap bekerja di dalam perusahaan, hal ini menjadikan lingkungan kerja yang nyaman dan kondusif. Hasil penelitian ini mendukung dengan hasil penelitian sebelumnya yang dilakukan oleh Celik,Dedeoglu, dan Inanir (2015), menunjukkan adanya hubungan positif yang signifikan antaraetika kepemimpinan dengan komitmen organisasi merupakan sebuah proses yang terbentuk dalam waktu panjang dan akan menentukan karakteristik organisasi memiliki nilai-nilai positif ,sesuai dengan hasil penelitian yang menyatakan bahwa pengaruh etika kepemimpinan terhadap Komitmen Organisasi ditunjukkan dengan nilai beta sebesar 0,701 dan nilai signifikan lebihdari 0,05 ( $\beta=0,701$; p-value $<0,05)$.

\section{Hipotesis Dua}

Berdasarkan hasil uji hipotesis dua menunjukan bahwa Komitmen Organisasi berpengaruh positif terhadap Kepuasan Kerja. Karyawan yang memiliki komitmen organisasi menunjukan suatu keadaan dimana seseorang karyawan memihak organisasi tertentu serta tujuan-tujuan dan keinginannya untuk mempertahankan keanggotaan dalam organisasi tersebut. Semakin karyawan tetap ingin bekerja di dalam perusahaan membuat karyawan semakinmemiliki penilaian positif terhadap pekerjaan yang dimilikinya. Karyawan tersebut telahmelakukan evaluasi terhadap pekerjaan secara keseluruhan. Komitmen organisasi mampu memotivasi dengan menggerakkan seseorang karyawan untuk bekerja lebih baik dengan memberikan kontribusi terhadap tingkat efektifitas dan suksesnya suatu organisasi dimana mereka bernaung yang mampu menghasilkan suatu kepuasan kerja bagi para karyawan dalam perusahaan tersebut. Hasil penelitian ini mendukung dengan hasil penelitian sebelumnya yang dilakukan oleh Celik, Dedeoglu, dan Inanir (2015), yang menyatakan bahwa pengaruh Komitmen Organisasi terhadapkepuasan kerja ditunjukkan dengan nilai beta sebesar 0,373dan nilai signifikan kurang dari $0,01(\beta=$ 0,373; $p$-value $<0,05)$. Hasil penelitiannya menjelaskan bahwa kepuasan kerja karyawan diakibatkan oleh etika kepemimpinan yang baik dan komitmen organisasi perusahaan sehingga hal $d$ tersebut mampu meningkatkan produktifitas kerja karyawan. 


\section{Hipotesis Tiga}

Berdasarkan hasil uji hipotesis tiga menunjukkan bahwa etika kepemimpinan berpengaruh positif terhadap kepuasan kerja karyawan. Etika kepemimpinan dapat menciptakan kepemimpinan yang efektif dan efisien sehingga dapat mencapai tujuan yang telah ditetapkan oleh perusahaan.Semakin baik etika yang ada didalam perusahaan membuat karyawan memiliki perasaan senangketika bekerja didalam perusahaan. Hasil penelitian ini mendukung dengan hasil penelitian sebelumnya yang dilakukan oleh Celik,Dedeoglu, dan Inanir (2015), yang menyatakan bahwa pengaruh etika kepemimpinan terhadapkepuasan kerja ditunjukkan dengan nilai beta sebesar 0,401 dan nilai signifikan kurang dari0,05 ( $\beta=0,401 ; p$-value $<0,05)$.Hasil penelitiannya menjelaskan bahwa kepuasan kerja karyawan diakibatkan oleh etikakepemimpinan yang baik dan komitmen organisasi perusahaan sehingga hal tersebut mampu meningkatkan produktifitas kerja karyawan.

\section{DAFTAR PUSTAKA}

Abdulla, J., Djebarni, R., and Mellahi, K. (2011), "Determinants of job satisfaction inthe UAE: A case study of the Dubai police", Personnel review, Vol. 40 No.(1),pp. 126-146.

Celik, S., Dedeoglu, B.B. ve Inanır, A. (2015), "Relationship between
EthicalLeadership, Organizational Commitment and Job Satisfaction at HotelOrganizations", Ege Academic Review, Vol.15 No.1, pp. 53-63.

Frisch, C. and Huppenbauer, M. (2014), "New Insights into Ethical Leadership:

AQualitative Investigation of the Experiences of Executive Ethical Leaders",Journal of Business Ethics, Vol. 123, pp. 2343.

Fritz, J., O'Neil, N., Popp, A., Williams, C., \& Arnett, R. (2013). "The influence ofsupervisory behavioral integrity on intent to comply with organizational ethicalstandards and organizational commitment", Journal of Business Ethics, Vol.114, pp. 251-263.

Ghazzawi, I. (2008), "Job satisfaction antecedents and consequences: a newconceptual framework and research agenda", The Business Review, Vol. 11, pp.1-11.

Robbin, S. P. and Judge, T. A. 2012. Perilaku Organisasi, Edisi 12 : Salemba Empat, Jakarta.

Shin, Y. (2012), "CEO Ethical Leadership, Ethical Climate, Climate Strength, andCollective Organizational Citizenship Behavior", 
Journal of Business Ethics, Vol. 108, pp. 299-312.

Tumasjan, A., Strobel, M. and Welpe, I. (2010), "Ethical Leadership EvaluationsAfter Moral Transgression: Social Distance Makes the Difference", Journalof Business Ethics, Vol. 99, pp.609-622. 